\title{
IIMIII Impact of Collaborative Care for Underserved Patients with PTSD in Primary Care: a Randomized Controlled Trial
}

\author{
Lisa S. Meredith, Ph.D. 1,2 , David P. Eisenman, M.D., M.S.H.S. ${ }^{1,3}$, Bing Han, Ph.D. ${ }^{\text {, }}$, \\ Bonnie L. Green, Ph.D. ${ }^{4}$, Stacey Kaltman, Ph.D. ${ }^{4}$, Eunice C. Wong, Ph.D. ${ }^{1}$, Melony Sorbero, Ph.D. ${ }^{5}$, \\ Christine Vaughan, Ph.D. ${ }^{7}$, Andrea Cassells, M.P.H. ${ }^{6}$, Douglas Zatzick, M.D. ${ }^{7}$, Claudia Diaz, Ph.D. ${ }^{8}$,

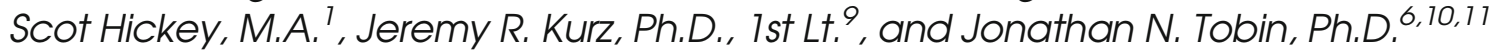

'RAND Corporation, Santa Monica, CA, USA; ${ }^{2}$ VA HSR\&D Center for the Study of Healthcare Innovation, Implementation \& Policy, Sepulveda, CA, USA; ${ }^{3}$ Division of General Internal Medicine and Health Services Research, Department of Medicine, David Geffen School of Medicine at UCLA, Los Angeles, CA, USA; ${ }^{4}$ Department of Psychiatry, Georgetown University Medical Center, Washington, DC, USA; ${ }^{5}$ RAND Corporation, Pittsburgh, PA, USA; ${ }^{6}$ Clinical Directors Network (CDN), New York, NY, USA; 'Department of Psychiatry and Behavioral Sciences, Harborview Injury Prevention and

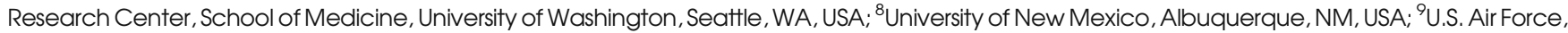
Esther, FL, USA; ${ }^{10}$ Department of Epidemiology and Population Health, Albert Einstein College of Medicine of Yeshiva University, Bronx, NY, USA;

${ }^{11}$ Center for Clinical \& Translational Science, The Rockefeller University, New York, NY, USA.

BACKGROUND: The effectiveness of collaborative care of mental health problems is clear for depression and growing but mixed for anxiety disorders, including posttraumatic stress disorder (PTSD). We know little about whether collaborative care can be effective in settings that serve low-income patients such as Federally Qualified Health Centers (FQHCs).

OBJECTIVE: We compared the effectiveness of minimally enhanced usual care (MEU) versus collaborative care for PTSD with a care manager (PCM).

DESIGN: This was a multi-site patient randomized controlled trial of PTSD care improvement over 1 year.

PARTICIPANTS: We recruited and enrolled 404 patients in six FQHCs from June 2010 to October 2012. Patients were eligible if they had a primary care appointment, no obvious physical or cognitive obstacles to participation, were age 18-65 years, planned to continue care at the study location for 1 year, and met criteria for a past month diagnosis of PTSD.

MAIN MEASURES: The main outcomes were PTSD diagnosis and symptom severity (range, 0-136) based on the Clinician-Administered PTSD Scale (CAPS). Secondary outcomes were medication and counseling for mental health problems, and health-related quality of life assessed at baseline, 6 months, and 12 months.

KEY RESULTS: Patients in both conditions improved similarly over the 1-year evaluation period. At 12 months, PTSD diagnoses had an absolute decrease of $56.7 \%$ for PCM patients and $60.6 \%$ for MEU patients. PTSD symptoms decreased by 26.8 and 24.2 points, respectively. MEU and PCM patients also did not differ in process of care outcomes or health-related quality of life. Patients who actually engaged in care management had mental health care visits that were $14 \%$ higher $(p<0.01)$ and mental health medication prescription rates that were $15.2 \%$ higher $(p<0.01)$ than patients with no engagement.

Received May 29, 2015

Revised September 4, 2015

Accepted January 4, 2016

Published online February 5, 2016
CONCLUSIONS: A minimally enhanced usual care intervention was similarly effective as collaborative care for patients in $\mathrm{FQHCs}$.

KEY WORDS: PTSD; primary care; community based interventions; mental health; medicaid.

\section{ABBREVIATIONS \\ PCC Primary care clinician \\ FQHC Federally qualified health center \\ PTSD Posttraumatic stress disorder \\ PCM PTSD care management \\ MEU Minimally enhanced usual care \\ $\mathrm{J}$ Gen Intern Med 31(5):509-17 \\ DOI: $10.1007 / \mathrm{s} 11606-016-3588-3$ \\ ๑) Society of General Internal Medicine 2016}

\section{INTRODUCTION}

Posttraumatic stress disorder (PTSD) affects over $10 \%$ of adults, ${ }^{1,2}$ up to $23 \%$ in primary care settings, ${ }^{3-8}$ and is associated with poor functioning, quality of life, ${ }^{9-12}$ and financial costs to society. ${ }^{13,14}$ Evidence-based treatments for PTSD include the use of selected serotonin reuptake inhibitors, especially sertraline but also fluoxetine, as the first line of pharmacological treatment, and evidence-based psychotherapies-exposure therapy, cognitive-behavioral therapy, and eye movement desensitization and reprocessing, along with patient education and adjunctive support services. $^{15-17}$

Collaborative models of chronic mental illness care that coordinate between primary care and care managers (CMs) are a proven approach to improving depression care in primary care settings. ${ }^{8,18-20}$ There is growing evidence that such collaborative care interventions may be adapted and implemented to address PTSD as well. But PTSD treatment is less routine in primary care and its care is more challenging because of barriers at the patient, physician and practice levels. ${ }^{4,21-23}$ The 
Coordinated Anxiety Learning and Management (CALM) trial ${ }^{24}$ found that, for patients with PTSD recruited from private and mostly academic medical settings, improvement in outcomes was no different relative to usual care. ${ }^{25}$ The Re-Engineering Systems for the Primary Care of PTSD (RESPECT-PTSD) trial for veterans with PTSD did not find an intervention effect for symptoms or functioning. ${ }^{26} \mathrm{~A}$ third trial of telemedicinebased collaborative care for PTSD was effective for engaging veterans in psychotherapy and reducing symptoms, but only for those receiving cognitive-behavioral therapy. ${ }^{27}$ These mixed findings call for more research to test collaborative care for PTSD.

The purpose of the Violence and Stress Assessment (ViStA) study was to determine whether a care management intervention in primary care is effective in the context of Federally Qualified Health Centers (FQHCs). FQHCs, which provide "safety net" health care for low income, minority, and uninsured or underinsured persons, ${ }^{22}$ are less able to provide integrated mental health care than in the settings of prior studies. ${ }^{28,29}$ The treatment of PTSD in FQHCs may be particularly challenging because patients face high levels of clinical comorbidity and social service needs, but there are limited resources to meet these needs. ${ }^{30}$

ViStA compared the effectiveness of minimally enhanced usual care (MEU) to PTSD care management (PCM) in FQHCs. We hypothesized that patients in the PCM intervention would receive more mental health care and have better clinical outcomes than patients in the MEU intervention, because of the enhanced collaborative care and resources delivered through a care manager $(\mathrm{CM})$.

\section{METHODS}

\section{Design, Setting, and Patients}

The ViStA study was a patient-level randomized controlled trial to compare the effectiveness of MEU with $\mathrm{PCM}^{6}{ }^{6} \mathrm{We}$ recruited and enrolled patients from six FQHCs in New York and New Jersey from June 2010 to October 2012. These FQHCs were members of Clinical Directors Network (CDN), a primary care Practice-Based Research Network. The RAND and CDN Institutional Review Boards approved the study protocol.

We used a two-staged recruitment procedure. Patients were approached by study recruitment coordinators in the FQHC waiting rooms and screened for eligibility: having an appointment with a primary care clinician (PCC), no obvious physical or cognitive obstacles to the assessment, age 18-65 years, and planning to continue care at that center for 1 year. Eligible patients completed a brief six-item PTSD screener before their appointment. ${ }^{31}$ Those positive on the screener completed the Clinician-Administered PTSD Scale (CAPS), ${ }^{32,33}$ a clinical, structured interview based on the DSM-IV (validated in Spanish) in the clinic or by telephone. We enrolled patients who met criteria for a PTSD diagnosis and provided informed consent. Eligible patients were randomized into the MEU and PCM conditions and were evaluated prior to the start of the interventions and at 6 and 12 months following intervention initiation. We conducted the study in Spanish and English.

\section{ViStA Interventions}

The ViStA intervention is detailed in Meredith et al. (2014). ${ }^{6}$ Briefly, the MEU intervention consisted of PCC education about trauma, PTSD, and evidence-based psychopharmacology. Prior to implementing the intervention, we delivered a 2-hour training onsite at each $\mathrm{FQHC}$ at the start of the study and two booster training sessions via Webcast during the intervention period. We trained $\mathrm{FQHC}$ clinicians on evidence-based medication for PTSD based on the National Institute for Clinical Excellence guidelines ${ }^{34}$ and provided PCCs with a laminated medication guide. We also informed PCCs about patients' PTSD diagnoses. Patients who were identified as having a PTSD diagnosis received a National Institute of Mental Health (NIMH) PTSD brochure. ${ }^{35}$

The PCM intervention included the MEU components plus components facilitated by CMs hired for the study. CMs were bachelors-level, half-time research staff, bilingual (in Spanish) with experience working in FQHC settings. These additional components were: active patient education and engagement using NIMH PTSD brochures and motivational interviewing techniques. ${ }^{36} \mathrm{CMs}$ also provided linkages to community resources with locally tailored information. CMs had structured cross-disciplinary communication with PCCs and mental health providers, plus weekly case management meetings supervised by the study psychiatrist to guide clinical care decisions. CMs facilitated continuity of care through an initial in-person visit in conjunction with a scheduled medical visit with the PCC, and up to 14 additional follow-up contacts, by phone or in-person, over 1 year.

\section{Assessments}

Patients were evaluated at baseline, 6 months, and 12 months via in-person or telephone by interviewers blinded to study assignment. Assessments were conducted in Spanish for $12.4 \%$ of the sample. The primary outcomes were PTSD diagnosis and symptom severity based on past month CAPS criteria for PTSD. CAPS severity was scored by summing the ratings (from 0 to 4 ) for frequency and intensity across each of the 17 symptom items for a possible range of $0-136$, with a higher score indicating greater severity and a score of 65 or above recommended for comprehensive psychological evaluation.

Secondary outcomes included self-reported measures of the process of care - the percent of patients who: 1) were prescribed a medication for a mental health problem, 2) had any mental health care visit, and 3) had any mental health care visit 
for psychotherapy (among those with any mental health care visit). We assessed health-related quality of life using the physical and the mental health composite scores from the 12-item Short-Form Health Survey. ${ }^{37}$

\section{Statistical Analysis}

ViStA was powered to detect a moderately small effect size with a statistical power $>0.8$ and two-sided $p$-value $<0.05$, a planned sample size of 400 and a $20 \%$ attrition rate. The detectable effect size is between 0.19 and 0.32 SD for a numeric outcome (e.g., PTSD severity score and physical health quality of life), and between 7 and 15 percentage points for a binary outcome (e.g., PTSD diagnosis and any use of mental health care utilization). The actual sample size was 404 and attrition from study enrollment to baseline interview completion was $12 \%$, yielding a sample of 355 completers. We used the sequential imputation method ${ }^{38}$ to impute missing data in the 6- or 12-month assessment. This method imputes data with complex missing patterns under the standard missing at random assumption. To account for the uncertainty in the imputed data, we generated five imputed data sets and analyzed them combined using the standard multiple imputation procedure. ${ }^{39}$

Per protocol, we first ran an intent-to-treat (ITT) analysis by the linear mixed-effect model to estimate the difference between PCM and MEU for primary and secondary outcomes at 6 and 12 months. We jointly modeled the outcomes at the three waves by time, condition, and the time by condition interaction, where time was a categorical variable to allow for different effects at 6 and 12 months. We controlled for interview mode (telephone vs. in-person), which was not randomized, and used random effects to account for correlations within sites and patients. Since the proportion of PCM assigned patients who engaged in PCM was relatively low (73\%), we conducted a post-hoc as-implemented analysis to estimate the association between all outcomes and the actual engagement of PCM, i.e., between patients for whom we were unable to schedule the initial face-to-face visit to start the PCM intervention and all other patients (PCM patients who did not engage in the intervention and MEU patients). To correct for the bias due to patients' engagement in the PCM, we used the inverse propensity score (PS) weighting method. ${ }^{40,41}$ The PS was a conditional probability of engaging in $\mathrm{PCM}$, which is equal to the product of the probability of being randomized to the PCM condition and the conditional probability of engaging in the PCM condition given observed patient characteristics and baseline outcomes. We weighted patients who engaged in PCM by the inverse of their PS, and all other patients by the inverse of one minus their PS. We applied multiple comparison adjustments by types of outcomes and types of analyses. All analyses were performed in SAS 9.

Baseline covariates included age, gender, race and ethnicity, education, foreign born, comfort speaking English, marital status, having at least one child, and insurance type. We adjusted for medical comorbidity, number of traumatic events experienced, probable diagnosis of major depression (PHQ9), ${ }^{42}$ physical disability, ${ }^{43}$ perceived stress ${ }^{44}$; emergency room, mental health, and substance abuse treatment utilization, and use of community services. We controlled for history of childhood sexual or physical abuse, severe anxiety (GAD$7){ }^{45}$ severe somatic symptoms (PHQ-15) ${ }^{42}$ hazardous alcohol use (AUDIT), ${ }^{46}$ probable drug abuse/dependence (DAST), ${ }^{47,48}$ interview mode (in-person or telephone) and study site. Details about these measures are provided in Meredith et al. ${ }^{6}$

\section{RESULTS}

\section{Sample Selection, Attrition, and Description}

Figure 1 shows the study screening and recruitment flow. We approached 8422 patients; $77 \%$ met eligibility criteria; $75 \%$ took the brief screener, and $20 \%$ scored positive for probable PTSD. Most of the screener positive patients consented to participate in the study $(61 \%)$ and were assessed with the CAPS. Among those assessed, $69 \%$ were diagnosed with PTSD and were randomized. Overall, $88 \%$ of the randomized patients completed the baseline interview, $71 \%$ completed the 6-month interview, and $80 \%$ completed the 12-month interview.

Among the 184 PCM patients, only 134 completed the initial visit to both the $\mathrm{CM}$ and the PCC (73\%); $10 \%$ of those patients never completed a telephone follow-up with the $\mathrm{CM}$. Only $11 \%$ completed at least half of the intended 14 followups. The average number of follow-ups was 4.2 , representing only a $28 \%$ dose of the planned visits.

The average age of the baseline participants was 42 years old (Table 1). The sample included mostly women $(80.6 \%)$, and a high proportion of Hispanic $(51.8 \%)$ and black (35.4\%) patients. Nearly $40 \%$ had less than a high school education and $19.6 \%$ were born outside the U.S. Most had Medicaid (81.2\%) or were uninsured (7.4\%). A high proportion had comorbid medical conditions $(67 \%)$, multiple traumatic events $(97.1 \%)$, high levels of PTSD severity (70.6 points overall), major depression $(51.6 \%)$, anxiety $(45.2 \%)$, severe somatic symptoms $(33.2 \%)$, hazardous alcohol use $(18.4 \%)$, or probable drug abuse/dependence $(8.8 \%)$. We found no baseline differences between the intervention conditions for these characteristics. Although there are some differences between the groups by actual intervention engagement of PCM vs. no actual engagement, none of these differences remained after adjusting for propensity score weighting.

\section{PTSD Diagnosis and Symptoms}

Table 2 shows the estimates by both study arm and actual engagement vs. no engagement for CAPS PTSD 


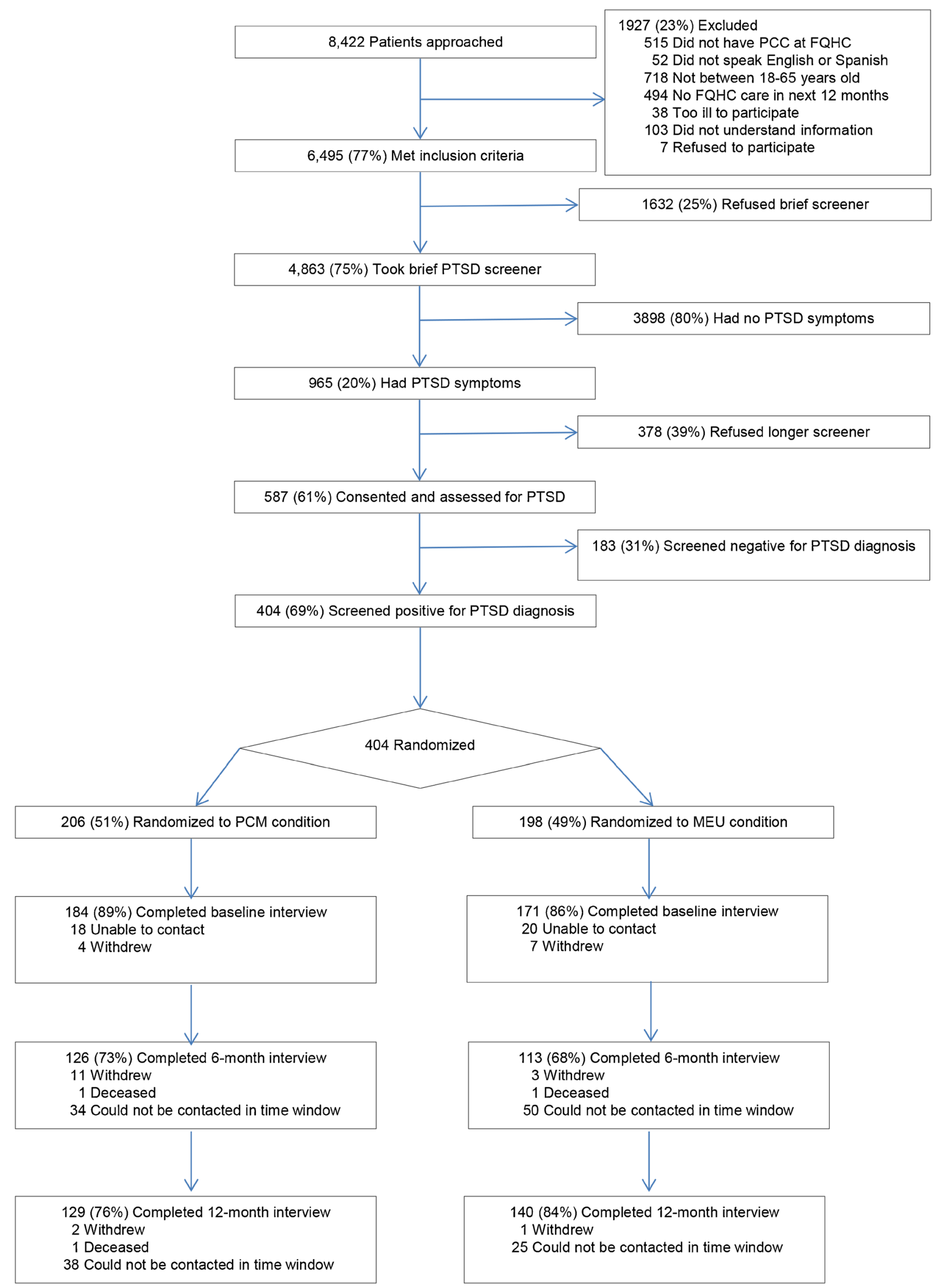

Figure 1. ViStA screening and enrollment flow. 
Table 1. Baseline Patient Characteristics ${ }^{\mathrm{a}}$

\begin{tabular}{|c|c|c|c|c|c|}
\hline \multirow[t]{2}{*}{ Characteristics } & \multicolumn{5}{|c|}{ No. (\%) of patients } \\
\hline & All $(N=355)$ & $\begin{array}{l}\text { PCM intervention } \\
\text { ITT }(N=184)\end{array}$ & $\begin{array}{l}\text { MEU intervention } \\
\text { ITT }(N=171)\end{array}$ & $\begin{array}{l}\text { Actual engagement } \\
\text { of } \mathrm{PCM}=\text { Yes } \\
(N=134)\end{array}$ & $\begin{array}{l}\text { Actual engagement } \\
\text { of PCM = No } \\
(N=\mathbf{2 2 1})\end{array}$ \\
\hline Age, mean (SD), y & $42.4(12.2)$ & $42.5(12.4)$ & $42.2(12.0)$ & $41.7(12.2)$ & $43.6(12.1)$ \\
\hline Women & $286(80.6)$ & $150(81.5)$ & $136(79.5)$ & $108(80.6)$ & $178(80.5)$ \\
\hline \multicolumn{6}{|l|}{ Race/ethnicity ${ }^{\mathrm{b}}$} \\
\hline Hispanic & $183(51.8)$ & $95(51.6)$ & $88(52.1)$ & $69(51.5)$ & $114(51.6)$ \\
\hline Black & $125(35.4)$ & $65(35.3)$ & $60(35.5)$ & $48(35.8)$ & $77(34.8)$ \\
\hline White & $21(6.0)$ & $14(7.6)$ & $7(4.1)$ & $9(6.7)$ & $12(5.4)$ \\
\hline Other & $24(6.8)$ & $10(5.4)$ & $14(8.3)$ & $8(6.0)$ & $16(7.2)$ \\
\hline \multicolumn{6}{|l|}{ Education* } \\
\hline$<$ High school & 137 (38.9) & $77(42.1)$ & $60(35.5)$ & $62(46.3)$ & $75(33.9)$ \\
\hline $12 \mathrm{y}$ & $116(33.0)$ & $54(29.5)$ & $62(36.7)$ & $38(28.4)$ & $78(35.3)$ \\
\hline$>12 \mathrm{y}$ & $99(28.1)$ & $52(28.4)$ & $47(27.8)$ & $34(25.4)$ & $65(29.4)$ \\
\hline Born outside of the U.S. ${ }^{\mathrm{c}}$ & 79 (19.6) & $43(19.4)$ & $36(17.7)$ & $26(19.4)$ & $53(24.0)$ \\
\hline \multicolumn{6}{|l|}{ Type of health insurance* } \\
\hline No insurance & $26(7.4)$ & $14(7.7)$ & $12(7.1)$ & $8(6.0)$ & $18(8.1)$ \\
\hline Medicaid & $286(81.2)$ & $150(82.4)$ & $136(80.0)$ & $105(78.4)$ & $181(81.9)$ \\
\hline Medicare & $7(2.0)$ & $3(1.6)$ & $4(2.4)$ & $3(2.2)$ & $4(1.8)$ \\
\hline Other government insurance & $20(5.7)$ & $10(5.5)$ & $10(5.9)$ & $10(7.5)$ & $10(4.5)$ \\
\hline Private insurance & $13(3.7)$ & $5(2.6)$ & $8(4.7)$ & $2(1.5)$ & $11(5.0)$ \\
\hline \multicolumn{6}{|l|}{ No. of chronic medical conditions* } \\
\hline 0 & $113(32.7)$ & $62(34.1)$ & $51(31.1)$ & $35(26.1)$ & $78(35.3)$ \\
\hline 1 & $73(21.1)$ & $36(19.8)$ & $37(22.6)$ & $30(22.4)$ & $43(19.5)$ \\
\hline 2 & $62(17.9)$ & $27(14.8)$ & $35(21.3)$ & $20(14.9)$ & $42(19.0)$ \\
\hline$\geq 3$ & $98(28.3)$ & $57(31.3)$ & $41(25.0)$ & $47(35.1)$ & $51(23.1)$ \\
\hline \multicolumn{6}{|l|}{ No. of lifetime traumas } \\
\hline 1 & $10(2.9)$ & $7(3.9)$ & $3(1.8)$ & $5(3.7)$ & $5(2.3)$ \\
\hline 2 & $29(8.3)$ & $17(9.4)$ & $12(7.1)$ & $12(9.0)$ & $17(7.7)$ \\
\hline$\geq 3$ & $311(88.9)$ & $157(86.7)$ & $154(91.1)$ & $114(85.1)$ & $197(89.1)$ \\
\hline$\overline{\mathrm{C}} \mathrm{APS}$ severity score & $70.6(16.0)$ & $70.5(15.8)$ & $70.6(16.1)$ & $71.5(16.2)$ & $70.0(15.8)$ \\
\hline Probable major depression ${ }^{\mathrm{d}}$ & $181(51.6)$ & $92(50.3)$ & $89(53.0)$ & $70(52.2)$ & $111(50.2)$ \\
\hline Severe anxiety symptoms $\mathrm{e}_{\mathrm{f}}$ & $160(45.2)$ & $80(43.7)$ & $80(46.8)$ & $59(44.0)$ & $101(45.7)$ \\
\hline Severe somatic symptoms ${ }^{\mathrm{f}}$ & $116(33.2)$ & $63(35.2)$ & $53(31.2)$ & $49(36.6)$ & $67(30.3)$ \\
\hline Hazardous alcohol use $\mathrm{g}^{\mathrm{g}}$ & $65(18.4)$ & $30(16.4)$ & $35(20.5)$ & $22(16.4)$ & $43(19.5)$ \\
\hline Probable drug abuse/dependence ${ }^{h}$ & $31(8.8)$ & $15(8.2)$ & $16(9.4)$ & $12(9.0)$ & $19(8.6)$ \\
\hline
\end{tabular}

${ }^{a}$ There were no significant differences between the PCM and MEU interventions

${ }^{b}$ Three $M E U$ patients $M E U$ did not disclose this information

${ }^{c}$ Sixteen patients (nine PCM and seven MEU) did not disclose this information

${ }^{d}$ Whether respondent meets criteria for a probable diagnosis of major depressive disorder on the PHQ-9, as indicated by presence of at least one of the two MDD symptoms of anhedonia or feeling down, depressed, or hopeless and at least five of the nine depressive symptoms for at least more than half the days over the past 2 weeks

${ }^{e}$ Severe anxiety as indicated by a cut-point of 15 on the GAD-7

${ }^{f}$ Severe somatization as indicated by a cut-point of 15 on the PHQ-15

${ }^{g}$ Hazardous alcohol use as indicated by a total AUDIT score of 8 or higher for men and 5 or higher for women

${ }^{h}$ Positive screen for or probable diagnosis of drug abuse/dependence as indicated by a total score of 3 or higher on the DAST-10

*Significant difference between actual treatment statuses. No variables had significant differences after adjusting for compliance propensity score

diagnosis and symptoms. The estimated intervention and engagement effects show no significant differences at 6 or 12 months. The proportion of patients with a PTSD diagnosis decreased significantly in both conditions over the 1 -year evaluation period $(p<0.0001)$, but did not differ significantly by treatment assignment $(p=0.34)$. At 12 months, PTSD diagnoses had an absolute decrease of $56.7 \%$ for PCM patients and by $60.6 \%$ for MEU patients (i.e., to rates of 43.3 and $39.4 \%$, respectively). CAPS symptom severity scores had an absolute decrease of 24.2 and 26.8 points for MEU and PCM conditions, respectively $(p<0.0001)$, but the difference between the two conditions was not significant $(p=0.33)$. These effects are equivalent to a $1.1 \mathrm{SD}$ change from baseline to 6 months within study arm and $0.08 \mathrm{SD}$ between study arms. The as-implemented analysis showed similar results.

\section{Process of Care and Health-Related Quality of Life}

There was no significant effect by study randomization condition on any process of care outcome or health-related quality of life at any wave (Table 3). Patients engaged in the PCM intervention had significantly higher rates of receiving prescriptions for mental health medications (a $15.2 \%$ difference, $p<0.01$ ) and mental health visits (a $14 \%$ difference, $p<0.01$ ) compared to all other patients at 6 months. We found no differences for health-related quality of life scores 
Table 2. PTSD Outcomes Based on the CAPS ${ }^{\text {a }}$

\begin{tabular}{|c|c|c|c|c|c|c|}
\hline Measure and wave & $\begin{array}{l}\text { PCM intervention } \\
\text { ITT }^{\mathbf{b}}(N=184)\end{array}$ & $\begin{array}{l}\text { MEU intervention } \\
\text { ITT }^{\text {b }}(N=171)\end{array}$ & $p$ Value & $\begin{array}{l}\text { Actual engagement of } \\
\text { PCM }=\text { Yes }(N=134)^{c}\end{array}$ & $\begin{array}{l}\text { Actual engagement of } \\
\mathrm{PCM}=\operatorname{No}(N=221)^{\mathrm{c}}\end{array}$ & $p$ Value \\
\hline \multicolumn{7}{|c|}{ PTSD diagnosis $(\%, 95 \% \mathrm{CI})$} \\
\hline Baseline & 100 & 100 & $\mathrm{n} / \mathrm{a}$ & 100 & 100 & $\mathrm{n} / \mathrm{a}$ \\
\hline 6 months & $50.4(44.1,56.7)$ & $50.9(39.0,62.7)$ & 0.94 & $49.0(38.3,59.8)$ & $46.9(40.0,53.8)$ & 0.73 \\
\hline 12 months & $43.3(39.5,47.2)$ & $39.4(28.8,51.1)$ & 0.34 & $41.6(31.8,51.5)$ & $39.4(32.7,46.1)$ & 0.71 \\
\hline \multicolumn{7}{|c|}{ PTSD symptom severity (mean, $95 \% \mathrm{CI}$ ) } \\
\hline Baseline & $71.1(67.9,74.3)$ & $71.0(67.9,74.2)$ & 0.97 & $69.5(65.7,73.4)$ & $70.4(68.2,72.6)$ & 0.69 \\
\hline 6 months & $47.8(44.2,51.3)$ & $49.5(46.4,52.6)$ & 0.54 & $48.4(43.1,53.7)$ & $47.6(44.1,51.2)$ & 0.81 \\
\hline 12 months & $46.9(42.8,50.9)$ & $44.2(41.2,47.1)$ & 0.33 & $48.2(43.2,53.2)$ & $43.6(39.8,47.4)$ & 0.11 \\
\hline
\end{tabular}

${ }^{a}$ CAPS Clinician Administered PTSD Scale

${ }^{b}$ Estimates and raw $p$ values for ITT analyses were based on longitudinal model predictions

${ }^{c}$ Estimates and raw $p$ values for as-implemented analyses were based on inverse propensity score weighting

by randomization conditions or by actual engagement of PCM.

\section{DISCUSSION}

ViStA is the first study to compare interventions for improving the management of PTSD in low resource, FQHCs. FQHCs lack the integrated mental health care that is more readily available in many private and VA primary care settings. Plus, patients seen in FQHCs are poorer, suffer from more medical illness and trauma, and are underinsured. ${ }^{30}$ Yet, both PCM and MEU groups improved substantially over the 1-year evaluation period with remission rates as high as 56.7 and $60.6 \%$; and symptom reductions of 24.2 and 26.8 points for PCM and MEU patients, respectively. While we expected greater improvement in the PCM arm that added collaborative care, it is important to note that these improvements are clinically significant and larger than the magnitude observed in other trials. ${ }^{25,27}$ Relative decreases in PTSD diagnoses were above $50 \%$ and symptom reduction was above $30 \%$ for both the MEU and PCM groups. A possible explanation for this striking level of improvement is that ViStA enrolled a sample of patients with less severe PTSD that may have a more favorable prognosis. Alternatively, these particular FQHCs could have been better positioned to implement care improvements for PTSD. However, we know that only three of the six FQHCs had onsite behavioral health.

The lack of a difference by intervention intensity suggests that identifying patients with PTSD diagnoses and giving that feedback to PCCs, combined with clinician education, may be effective for patients in FQHCs. At the end of the 12-month assessment period, over half of the study patients no longer met criteria for a PTSD diagnosis across condition. Given the similarity of effectiveness, it appears that the addition of collaborative care in these settings was not more effective in this current form.

Another reason why we observed similar effects in both interventions is that even the care that patients received in the MEU group was still more than is typically delivered in these under-resourced health centers. However, the rate of nonadherence was relatively high among patients in the PCM intervention; only $73 \%$ of the PCM patients completed the initial face-to-face visit with the CM and PCC. By comparison, in RESPECT-PTSD, ${ }^{26} 89 \%$ of the veteran participants referred to the program established contact. ${ }^{3}$ The treatment arm in the CALM study had an adherence rate of $96 \% .{ }^{19} \mathrm{In}$ ViStA, the intervention dose for the PCM intervention was also lower than intended among the as-implemented group with only four of 14 contacts with the CM on average.

Table 3. Process of Care and Health-Related Quality of Life by Study Intervention Condition

\begin{tabular}{|c|c|c|c|c|c|c|}
\hline Measure and wave & $\begin{array}{l}\text { PCM intervention } \\
\text { ITT }^{\mathbf{b}}(N=184)\end{array}$ & $\begin{array}{l}\text { MEU intervention } \\
\text { ITT }^{\mathbf{b}}(N=171)\end{array}$ & $p$ Value & $\begin{array}{l}\text { Actual engagement of } \\
\mathrm{PCM}=\text { Yes }(N=134)^{\mathrm{c}}\end{array}$ & $\begin{array}{l}\text { Actual engagement of } \\
\mathrm{PCM}=\operatorname{No}(N=221)^{\mathrm{c}}\end{array}$ & $p$ Value \\
\hline \multicolumn{7}{|c|}{ Any mental health prescription $(\%, 95 \% \mathrm{CI})$} \\
\hline Baseline & $40.7(35.7,45.8)$ & $42.2(35.6,48.8)$ & 0.44 & $40.6(47.7,31.3)$ & $40.5(33.6,47.7)$ & 0.98 \\
\hline 6 months & $47.2(39.1,55.3)$ & $41.2(34.4,48.0)$ & 0.24 & $54.2(43.9,64.6)$ & $39.0(31.9,46.0)$ & $0.01^{\mathrm{d}}$ \\
\hline 12 months & $42.9(35.3,50.6)$ & $45.4(38.0,52.9)$ & 0.69 & $48.8(38.6,59.1)$ & $43.9(36.4,51.4)$ & 0.42 \\
\hline \multicolumn{7}{|c|}{ Any mental health care utilization $(\%, 95 \% \mathrm{CI})$} \\
\hline Baseline & $64.6(57.8,71.4)$ & $69.0(64.4,73.5)$ & 0.12 & $61.4(50.6,72.4)$ & $63.7(57.2,70.1)$ & 0.73 \\
\hline 6 months & $74.1(64.7,83.4)$ & $66.6(56.4,76.8)$ & 0.29 & $78.0(69.6,86.4)$ & $64.0(54.4,73.7)$ & $0.01^{\mathrm{d}}$ \\
\hline 12 months & $59.9(52.2,67.5)$ & $60.7(53.4,68.0)$ & 0.85 & $68.6(58.8,78.4)$ & $58.4(51.5,65.3)$ & 0.30 \\
\hline \multicolumn{7}{|c|}{ Any mental health counseling $(\%, 95 \% \mathrm{CI})$} \\
\hline Baseline & $40.3(29.3,51.2)$ & $45.0(35.2,54.7)$ & 0.24 & $40.5(31.1,49.8)$ & $41.9(35.2,48.6)$ & 0.81 \\
\hline 6 months & $44.1(34.3,54.0)$ & $43.4(36.9,49.9)$ & 0.89 & $47.2(36.2,58.1)$ & $43.0(34.6,51.4)$ & 0.51 \\
\hline 12 months & $46.1(38.2,53.9)$ & $43.3(32.7,53.9)$ & 0.69 & $52.1(41.7,62.5)$ & $42.2(35.1,49.2)$ & 0.11 \\
\hline
\end{tabular}

${ }^{a}$ All measurements were for the 6-month period before the measurement time

${ }^{b}$ Estimates and raw $p$ values for ITT analyses were based on longitudinal model predictions

${ }^{c}$ Estimates and raw p values for as-implemented analyses were adjusted by propensity score weighting

${ }^{d}$ Significant after multiple comparison adjustment at the false discovery rate $<0.05$ 
However, even this low dose is comparable to studies with more intense interventions, and this amount of exposure yielded more overall clinical benefit than has been seen in some trials consisting of only a single brief intervention. ${ }^{49}$ A potential explanation for the improvement in PTSD diagnosis and severity score at 6 months is regression to the mean. That is, patients were enrolled on the basis of initial high PTSD severity scores. This may have made the subsequent measurements moving toward the true means, which would be lower than the average of the initial measurement.

These findings, taken together with results from previous studies of collaborative care for PTSD (RESPECT-PTSD and collaborative telehealth for veterans) ${ }^{27}$ suggest that this approach is not a promising strategy for treating PTSD by itself. Further trials of PTSD collaborative care are still needed to understand how to improve these interventions to implement the most effective strategies possible in these settings that serve mostly low-income and minority populations. It is unclear whether a more intensive intervention that pairs manualized therapy with trained mental health professionals would have engaged more patients, given our difficulty in engaging patients in a few sessions with CMs. A less intensive intervention may be more practical in this population, because it is less burdensome. It is worth noting that the PCM intervention enabled more patients to access mental health care, primarily psychoactive medication. This makes sense: ViStA emphasized training PCCs on appropriate prescribing rather than training mental health providers to deliver manualized therapy, ${ }^{50}$ because of the limited availability of on-site mental healthcare for improving access to evidence-based psychotherapies. The quality of mental health care accessible to low-income, minority communities is a considerable concern; mental health professionals who can provide evidence-based and culturally competent care are in short supply in the neighborhoods served by our FQHCs. ${ }^{51-53}$

Our findings suggest that patients in FQHCs benefitted from PCC education and feedback, as well as from the addition of care management. In studies that have included a true usual care comparison group, outcomes improved for the interventions, but not for usual care ${ }^{54,55}$ However, given the higher intensity of adding collaborative care, the MEU intervention showed similar effectiveness. It remains to be seen whether adding collaborative care more intensively can increase impact for this patient population. This study highlighted some of the challenges faced with engaging this unique population in intensive interventions for PTSD and suggests a need to improve reach and impact with this population. The fact that patients only engaged on average 4.2 times with $\mathrm{CMs}$ suggests that the PCM intervention may have been too demanding for this population. The high levels of social disruption (e.g., unstable housing, food insecurity, and social isolation) experienced by this patient population beyond their trauma experiences and associated health consequences may have limited exposure to the intervention. Nevertheless, we have begun to fill a gap in knowledge about how to translate collaborative care interventions for FQHCs. Modifications to the intervention may be needed to enable patients to address these social determinants challenges. These modifications might involve exploring community outreach approaches (e.g., helping patients access mental health specialists) and additional tailoring (briefer and/or modularized treatments) for better fit within FQHCs. ${ }^{56}$

\section{Acknowledgments:}

Contributors: The authors appreciate the following Community Health Centers for partnering on the study: Morris Heights Health Center, Bronx, NY, Joseph P. Addabbo Health Center - Main Site, Far Rockaway, NY, Joseph P. Addabbo Health Center - Central Avenue, Far Rockaway, NY Ryan NENA Health Center, NY, NY, Soundview Health Center, Bronx, NY, Open Door Family Health Center, Port Chester, NY, Metropolitan Family Health Network, Jersey City, NJ. We acknowledge the clinicians and staff who participated in the advisory group, including Sara Ventre, RN, Gloria Leacock, MD, and Crystal Foy, BA, of Community Healthcare Network, NY, NY; Alfonso Chan, MD, Joseph P. Addabbo Health Center, Queens, NY; Lauren Machin, CSW, and Diane Traver, MD, of Morris Heights Health Center, Bronx, NY, Crystal Jordan, JD, Soundview Health Center; Arthur Berger, MD, Urban Health Plan, Bronx, NY; Harsha Tripathi, Plainfield Neighborhood Health Center, Plainfield, NJ. We also thank CDN staff, including: Marleny DiazGloster, MPH, Tzyy Jye Lin, MPH, Rosario Hinojosa, Jennifer Rodriguez, Tatiana Carillo, Mala Nimalasuriya, Carrie Goodman, MPH, Carmen Rodriguez, Ajeenah Haynes, PhD, Parisa Faysar, Elizabeth Leonard, Omesh Persaud, and Taralah Washington for their assistance in identifying, recruiting, interviewing, translating, and patient care management. We thank Dolly Dahdal, Catherine Chao, and Rosie Velasquez for help with project assistance and for manuscript preparation.

Funder: This research was supported by a grant to Dr. Meredith from the National Institute of Mental Health/NIMH (RO1MHO82768, R01MH082768-02S1, R01MH082768-04S1).

Prior Presentations: Earlier versions of this work were presented at the International Society for Traumatic Stress Society meetings (Philadelphia, PA, November 2013 and New Orleans, LA, November, 2016).

Corresponding Author: Lisa S. Meredith, Ph.D.; RAND Corporation, 1776 Main Street, Santa Monica, CA 90407-2138, USA (e-mail: lisa_meredith@rand.org).

\section{Compliance with Ethical Standards:}

Conflict of Interest: The authors declare that they do not have a conflict of interest.

\section{REFERENCES}

1. Kessler RC, Chiu WT, Demler O, Merikangas KR, Walters EE. Prevalence, severity, and comorbidity of 12-month DSM-IV disorders in the National Comorbidity Survey Replication. Arch Gen Psychiatry. 2005;62(6):617-627.

2. Schnurr PP, Spiro A 3rd, Paris AH. Physician-diagnosed medical disorders in relation to PTSD symptoms in older male military veterans. Health Psychol. 2000;19(1):91-97.

3. Gillock KL, Zayfert C, Hegel MT, Ferguson RJ. Posttraumatic stress disorder in primary care: prevalence and relationships with physical symptoms and medical utilization. Gen Hosp Psychiatry. 2005;27(6):392-399.

4. Liebschutz J, Saitz R, Brower V, Keane TM, Lloyd-Travaglini C, Averbuch T, Samet JH. PTSD in urban primary care: high prevalence and low physician recognition. J Gen Intern Med. 2007;22(6):719-726.

5. Magruder KM, Frueh BC, Knapp RG, Davis L, Hamner MB, Martin RH, et al. Arana GW. Prevalence of posttraumatic stress disorder in veterans affairs primary care clinics. Gen Hosp Psychiatry. 2005;27(3):169-179. 
6. Meredith LS, Eisenman DP, Green BL, Kaltman S, Wong EC, Han B, Tobin JN, et al. Design of the Violence and Stress Assessment (ViStA) study: a randomized controlled trial of care management for PTSD among predominantly Latino patients in safety net health centers. Contemp Clin Trials. 2014;38(2): 163-172.

7. Stein MB, McQuaid JR, Pedrelli P, Lenox R, McCahill ME. Posttraumatic stress disorder in the primary care medical setting. Gen Hosp Psychiatry. 2000;22(4):261-269.

8. Wells KB, Sherbourne C, Schoenbaum M, Duan N, Meredith L, Unützer $\mathbf{J}$, Rubenstein LV, et al. Impact of disseminating quality improvement programs for depression in managed primary care: a randomized controlled trial. JAMA. 2000;283(2):212-220.

9. Ettner SL, Frank RG, Kessler RC. The impact of psychiatric disorders on labor market outcomes. Ind Labor Relat Rev. 1997;51:64-81.

10. Kessler RC, Walters EE, Forthofer MS. The social consequences of psychiatric disorders, III: probability of marital stability. Am J Psychiatry. 1998;155(8):1092-1096.

11. Ouimette P, Cronkite R, Henson BR, Prins A, Gima K, Moos RH. Posttraumatic stress disorder and health status among female and male medical patients. J Trauma Stress. 2004;17(1):1-9.

12. Zayfert C, Dums AR, Ferguson RJ, Hegel MT. Health functioning impairments associated with posttraumatic stress disorder, anxiety disorders, and depression. J Nerv Ment Dis. $2002 ; 190(4): 233-240$.

13. Kessler RC. Posttraumatic stress disorder: the burden to the individual and to society. J Clin Psychiatry. 2000;61(Suppl 5):4-12. discussion 13-14.

14. Walker EA, Katon W, Russo J, Ciechanowski P, Newman E, Wagner AW. Health care costs associated with posttraumatic stress disorder symptoms in women. Arch Gen Psychiatry. 2003;60(4):369-374.

15. U.S. Department of Veteran Affairs. Management of Post-Traumatic Stress Disorder and Acute Stress Reaction (2010). VA/DoD Clinical Practice Guidelines 2010. Available at: http://www.healthquality.va.gov/guidelines/MH/ptsd/. Accessed October 4, 2015.

16. American Psychiatric Association. American Psychiatric Association Practice Guidelines. http://psychiatryonline.org/guidelines. Accessed October 4, 2015.

17. Agency for Healthcare Research and Quality. Psychological and Pharmacological Treatments for Adults With Posttraumatic Stress Disorder (PTSD). Comparative Effectiveness Review Number 922013. Available at: http://www.effectivehealthcare.ahrq.gov/ehc/products / 347/1435/PTSD-adult-treatment-report-130403.pdf. Accessed October 4, 2015.

18. Katon W, Robinson P, Von Korff M, Lin E, Bush T, Ludman E, Walker E, et al. A multifaceted intervention to improve treatment of depression in primary care. Arch Gen Psychiatry. 1996;53(10):924-932.

19. Simon GE, VonKorff M, Rutter C, Wagner E. Randomised trial of monitoring, feedback, and management of care by telephone to improve treatment of depression in primary care. BMJ. 2000;320(7234):550-554.

20. Unutzer J, Katon W, Callahan CM, Williams JW Jr, Hunkeler E, Harpole L, Treatment IIIM-PAtC, et al. Collaborative care management of late-life depression in the primary care setting: a randomized controlled trial. JAMA. 2002;288(22):2836-2845.

21. Koenen KC, Goodwin R, Struening E, Hellman F, Guardino M. Posttraumatic stress disorder and treatment seeking in a national screening sample. J Trauma Stress. 2003;16(1):5-16.

22. U.S. Department of Health \& Human Services. Health Center Data: 2014 National Data \& 2011 State Data - special tabulation. 2011. Available at: http://bphc.hrsa.gov/uds/datacenter.aspx. Accessed October 4, 2015.

23. Meredith LS, Eisenman DP, Green BL, Basurto-Davila R, Cassells A, Tobin $\mathbf{J}$. System factors affect the recognition and management of posttraumatic stress disorder by primary care clinicians. Med Care. 2009;47(6):686-694.

24. Roy-Byrne P, Craske MG, Sullivan G, Rose RD, Edlund MJ, Lang AJ, Stein MB, et al. Delivery of evidence-based treatment for multiple anxiety disorders in primary care: a randomized controlled trial. JAMA. 2010;303(19): 1921-1928.

25. Craske MG, Stein MB, Sullivan G, Sherbourne C, Bystritsky A, Rose RD, Roy-Byrne P, et al. Disorder-specific impact of coordinated anxiety learning and management treatment for anxiety disorders in primary care. Arch Gen Psychiatry. 2011;68(4):378-388.

26. Schnurr PP, Friedman MJ, Oxman TE, Dietrich AJ, Smith MW, Shiner B, Thurston V, et al. RESPECT-PTSD: re-engineering systems for the primary care treatment of PTSD, a randomized controlled trial. J Gen Intern Med. 2013;28(1):32-40.
27. Fortney JC, Pyne JM, Kimbrell TA, Hudson TJ, Robinson DE, Schneider R, Schnurr PP, et al. Telemedicine-based collaborative care for posttraumatic stress disorder: a randomized clinical trial. JAMA Psychiatry. 2015;72(1):58-67.

28. Scharf DM, Eberhart NK, Schmidt N, Vaughan CA, Dutta T, Pincus HA, Burnam MA. Integrating primary care into community behavioral health settings: programs and early implementation experiences. Psychiatr Serv. 2013;64(7):660-665.

29. Cook NL, Hicks LS, O'Malley AJ, Keegan T, Guadagnoli E, Landon BE. Access to specialty care and medical services in community health centers. Health Aff. 2007;26(5): 1459-1468.

30. Blumenthal D, Mort E, Edwards J. The efficacy of primary care for vulnerable population groups. Health Serv Res. 1995;30(1 Pt 2):253-273

31. Lang AJ, Stein MB. An abbreviated PTSD checklist for use as a screening instrument in primary care. Behav Res Ther. 2005;43(5):585-594.

32. Blake DD, Weathers FW, Nagy LN, Kaloupek DG, Klauminzer G, Charney DS, Keane TM. A clinician rating scale for assessing current and lifetime PTSD: the CAPS-1. Behav Ther. 1990;18:187-188.

33. Weathers FW, Keane TM, Davidson JRT. Clinician-administered PTSD scale: a review of the first ten years of research. Depress Anxiety. 2001;13(3):132-156.

34. National Institute for Clinical Excellence/NICE. Clinical guidelines CG26, Post-traumatic stress disorder (PTSD): The management of PTSD in adults and children in primary and secondary care. March 2005. Available at: http://www.nice.org.uk/cg26. Accessed October 4, 2015.

35. National Institute of Mental Health. Post-Traumatic Stress Disorder. 2008. Available at: http://www.nimh.nih.gov/health/publications/post-traumatic-stress-disorder-ptsd/index.shtml. Accessed October 4, 2015.

36. Miller WR, Rollnick S. Motivational interviewing: preparing people for change. 2nd ed. New York: Guilford Press; 2002.

37. Ware Jr. JE, Kosinski M, Keller S. SF-12: How to score the $\mathrm{SF}-12$ physical and mental health summary scales 2nd ed. Boston, MA: The Health Institute, New England Medical Center. 1995.

38. van Buuren S. Multiple imputation of discrete and continuous data by fully conditional specification. Stat Methods Med Res. 2007;16(3):219-242.

39. Little RJA, Rubin DB. Statistical analysis with missing data. 2nd ed. Hoboken: Wiley; 2002.

40. Luo Z, Gardiner JC, Bradley CJ. Applying propensity score methods in medical research: pitfalls and prospects. Med Care Res Rev MCRR. 2010;67(5):528-554.

41. Little RJ, Long $\mathbf{Q}$, Lin $\mathbf{X}$. A comparison of methods for estimating the causal effect of a treatment in randomized clinical trials subject to noncompliance. Biometrics. 2009;65(2):640-649.

42. Spitzer RL, Kroenke K, Williams JBW, Primary PHQ. Validation and utility of a self-report version of PRIME-MD - the PHQ primary care study. JAMA. 1999;282(18):1737-1744

43. Leon AC, Olfson M, Portera L, Farber L, Sheehan DV. Assessing psychiatric impairment in primary care with the Sheehan disability scale. Int J Psychiatr Med. 1997;27(2):93-105.

44. Cohen S, Kamarck T, Mermelstein R. A global measure of perceived stress. J Health Soc Behav. 1983;24(4):385-396.

45. Spitzer RL, Kroenke K, Williams JBW, Lowe B. A brief measure for assessing generalized anxiety disorder-the GAD-7. Arch Intern Med. 2006; 166(10):1092-1097.

46. Babor TF, Higgins-Biddle JC, Saunders JB, Monteiro MG. The alcohol use disorders identification test. Guidelines for use in primary care. 2001; 2.

47. Skinner HA. The drug-abuse screening-test. Addict Behav. 1982;7(4):363-371

48. Yudko E, Lozhkina O, Fouts A. A comprehensive review of the psychometric properties of the drug abuse screening test. J Subst Abuse Treat. 2007;32(2): 189-198.

49. Roy-Byrne P, Bumgardner K, Krupski A, Dunn C, Ries R, Donovan D, Zarkin GA, et al. Brief intervention for problem drug use in safety-net primary care settings a randomized clinical trial. JAMA. 2014;312(5):492-501

50. Foa EB, Gillihan SJ, Bryant RA. Challenges and successes in dissemination of evidence-based treatments for posttraumatic stress: lessons learned from prolonged exposure therapy for PTSD. Psychol Sci Public Interes J Am Psychol Soc. 2013;14(2):65-111.

51. Hetrick SE, Purcell R, Garner B, Parslow R. Combined pharmacotherapy and psychological therapies for post traumatic stress disorder (PTSD). Cochrane Db Syst Rev. 2010; (7)

52. Jones E, Ku L, Smith S, Lardiere M. County workforce, reimbursement, and organizational factors associated with behavioral health 
capacity in health centers. J Behav Health Serv Res. 2014;41(2): 125-139.

53. Tol WA, Barbui C, van Ommeren M. Management of acute stress, PTSD, and bereavement WHO recommendations. JAMA. 2013;310(5):477-478.

54. Miranda J, Chung JY, Green BL, Krupnick J, Siddique J, Revicki DA, Belin T. Treating depression in predominantly low-income young minority women—a randomized controlled trial. JAMA. 2003;290(1):57-65.
55. Wells KB, Sherbourne C, Schoenbaum M, Duan N, Meredith L, Unutzer $\mathbf{J}$, Rubenstein LV, et al. Impact of disseminating quality improvement programs for depression in managed primary care -a randomized controlled trial. JAMA. 2000;283(2):212-220.

56. Possemato K. The current state of intervention research for posttraumatic stress disorder within the primary care setting. J Clin Psychol Med Settings. 2011;18(3):268-280. 